\title{
" The effectiveness of a training programme in test-taking strategies on proficiency test performance among EfI trainees and their strategy knowledge use and value By:Dr. Attia Essayed Attia1"
}

\section{Abstract:}

The current study sought to empirically probe the effectiveness of informed testtaking strategy training programme on the American Language Course Placement Test performance, strategy knowledge, use as well as its perceived value among EFL military trainees. Fifty EFL military trainees who represent high elementary level of proficiency - book 7-12 of the American Language Course - participated in the study. The experimental group students $(n=27)$ were explicitly trained on an array of testtaking strategies (i.e., language learning strategies, test-wiseness strategies and testmanagement strategies) among which were previewing, avoiding similar sounds, listening for key words, listening for word definition, listening for synonyms and antonyms, using background knowledge and guessing unknown words, whereas the control group $(n=23)$ received regular classroom teaching with no emphasis on testtaking strategies. The findings revealed that performance of the students of the experimental group was significantly better than those of the control group on the ALCPT as well as in strategy knowledge, use and perceived value. The findings suggest some potential benefit in the overt test-taking strategy instruction as a means of helping learners better their test performance and scores as well as their repertoire and appreciation of test-taking strategy use. The findings suggest that we should start testtaking strategy instruction early, infuse test-taking strategy instruction into the curriculum, practice with actual testing formats and more preferable if we have past paper tests. In effect, the time devoted to test-taking strategies and how to beat the test techniques is well-invested, worth taking and has its own pay-off. Implications of this study for learner training, pedagogy and pre-service teacher training programs conclude the study.

Keywords : Test-taking strategies, informed test-taking strategy- modeling, training EFL students, American Language Course, American Language Course Placement Test, EFL Military trainees,

\section{Introduction :}

Testing is probably the primary means of evaluating students' performance in various educational settings. Indeed, tests are increasingly assuming the role of gate keepers in societies where access to programs depends on successful language test results (Shohamy, 2001). Language test results may play a highly significant role in the respondents' life, helping to determine whether test takers get into their study program of choice or get offered the job of their dreams. Parents expect test scores, educational authorities require them, college admission tutors rely on them and, in general, society uses them to distribute its job resources and career paths among the multiple applications (Dornyei, 2001).

1 Attia Es-Sayed Attia, Assistant Professer of TEFL and Team Leader \& Director of Academic Studies, Language School, MoD, Kuwait. E-mail: elhefnawy70@gmail.com. 
The current study came in reaction to the frequent complaint of EFL military adult trainees of the Language School, Ministry of Defense (henceforth MoD), Kuwait who are not achieving the required competence in American Language Course Placement Test (henceforth $A L C P T)$ and therefore they are disenrolled from the Military Language School due to lack of progress. During the Students Evaluation Board (SEB) 2 meetings, trainees frequently expressed their dissatisfaction and unhappiness about their poor performance on the ALCPT test. Furthermore, the statistics of trainees who have been disenrolled due to not achieving the target score on the ALCPT came up to $40 \%$ of the total enrolled trainees in 2008. Poor scores on the ALCPT might be due to the fact that those trainees lack the skills or strategies to cope with the requirements of the test and therefore they feel anxious and their memory resources are depleted. Put simply, they do not have the strategies or tools to achieve high scores on the ALCPT or to deal with the test strategically.

Recently, there has been an increasing interest in teaching test-taking strategies as tools that have considerable potential for improving learners' ability to deal with testing situation and its demands as well as to better learners' overall test score and performance. Advocates of testtaking strategies instruction argue that teaching test-taking strategies can ward off learners' test anxiety, reduce uncertainty, and help them be more relaxed and at ease about taking tests which in turn enhance their ability to deal with the testing situation more strategically (Amer, 1993; Derisbach and Keogh, 1982; Foster and Karn, 1998; Tian, 2000). More importantly, test-taking strategies can help learners manage their time more effectively and strategically (Obah, 1993), which, in turn, can bolster learners' motivation and self-confidence; a pre-requisite for better performance in any situation, including testing (Cohen, 1991, 2007; Green, 2007). The natural outcome of all such benefits is better test scores and a wide repertoire of effective test-taking strategies.

\section{Context of the study:}

Adult EFL military trainees at the Language School, MoD, Kuwait, study the American Language Course (henceforth ALC). The ALC is a

2 SEB is a panel of academicians and staff officers working at the language school whose responsibility is to monitor and evaluate trainees' progress and achievement during their study time at school. If a student fails twice, he is verbally warned, if again he can be warned up to three written warnings and then disenrolled due to lack of progress and is sent back to his unit. 
language course to introduce students to General English and military terms and expose them to American language and culture providing ample opportunities to put English into practice in a classroom setting. The ALC offers tuition from no English to that of professional advanced. The course, 34 books, was developed by the US Defense Language Institute, English Language Center (henceforth DLIELC), Lackland Air Force Base, Texas. These books are divided into six levels of proficiency, namely, Elementary (book 1-6), High Elementary (book 7-12), Intermediate (13-18), High Intermediate (19-24) Advanced (25-30) and Advanced Professional (31-34). These books are supplemented by audio language books and audio clips, and interactive computer media. The course comes with ALC Book Quizzes (i.e., achievement tests for assessing ALC objectives at the end of each book), The Performance Test (i.e., achievement test of the productive language skills given at the completion of each level), as well as 35 alternate forms of a proficiency test, namely the ALCPT. Once a new candidate is sent to the school, the sending unit assigns him a target score to obtain depending on why he is studying English, be it to raise his overall language proficiency or to be sent to a scholarship. Each student is placed at a starting book level depending upon his current level using the ALC Placement Test as well as an oral interview. Assignments can vary from 12 to 42 weeks. Each book is taught in a 2-week cycle. At the end of the first week, a mid-book test is given and at the end of the second week an end of book quiz (EBQ) is given. Each 4 weeks an ALCPT test is given to determine the learners' progress. These tests are all computer-based. ALCPT score is a threshold metric at the school, Military Language School. Not only do higher scores improve trainees' chance of acceptance at the Joint Command and Staff College, they may also lead to significant scholarships to pursue technical studies at the States or Britain.

\section{Statement of the Problem :}

Most of the EFL Military trainees at the Language School, MoD, Kuwait lack the needed skills or strategies to cope with the requirements of the ALCPT test to the extent that they often complain that when they listen to the audio in the ALCPT, they listen to blurry noises and they cannot recognize most of what is being said. However, they don't take the risk and try to employ certain strategies or tools to help themselves deal with the situation, nor do they even know that they can do so. Put simply, they do not have the ability or means to deal with the ALCPT 
strategically so as to achieve the target scores and in turn they get disenrolled due to lack of progress. The present study investigates the effectiveness of a test-taking strategy training programme on the ALCPT performance, strategy knowledge, use as well as perceived value among EFL military trainees. More specifically the present study tried to answer the following questions:

- What is the effectiveness of a suggested test-taking strategy training programme on the ALCPT performance among a sample of EFL military trainees?

- What is the effectiveness of a suggested test-taking strategy training programme on knowledge of test-taking strategies among a sample of EFL military trainees?

- What is the effectiveness of a suggested test-taking strategy training programme on use of test-taking strategies among a sample of EFL military trainees?

- What is the effectiveness of a suggested test-taking strategy training programme on perceived value of using test-taking strategies among a sample of EFL military trainees?

\section{Review of literature:}

Test-taking strategies simply mean what the test takers do or might do to solve test problems. They are the tactics test takers resort to with the aim of getting correct answers on a given test item or compensating for the lack of information that could aid their response to a given question. Test-taking strategies, in this sense, are perceived as compensatory since they are typically used by test-takers to make up for deficiency either in the language ability necessary to perform the test tasks, in the skill to take the test, or in both. They are, according to Cohen (2000) the consciously selected processes that the respondents use for dealing with both language issues and the item-response demands in the test-taking tasks at hand. More precisely, these strategies can either be a short move (e.g., looking for a clue that links the information in the question to that in the reading text) or a long one (e.g., reading the whole text after reading the question (Cohen, 1992, 1998).

Cohen (2006: 308) succinctly brings the focus of test-taking strategies into three types of strategies that may be called into play when attempting to respond to language test items and tasks, namely:

Language Learner Strategies (i.e., the way respondents operationalized their basic skills of listening, speaking, reading, and writing as well as the related skills of vocabulary learning, grammar and 
translation. To elaborate and for instance, as part of the assessment of listening skill, a listening comprehension item could call for inferencing strategies on the part of respondent while listening to a brief interchange. The listener hears the following: "Well, we could probably have it ready by 4 pm today but best to let us keep it overnight just to make sure all the updates have been probably installed" and they need to select the situation in which that utterance was most likely to appear:

- a bicycle store attendant to a patron

- a computer technician to the purchaser of a new computer

- a clerk at an auto repair service to a customer

- a music store clerk to the owner of a trumpet

The key word in this item is 'update', which refers to the readying of new computer. Some levels of inferencing are involved here since some may think that a computer is ready "out of the box", without the need for updating. It also calls for knowledge of vocabulary such as "patron". So we see that the processing of listening comprehension items of this kind are likely to prompt respondents to make use of language learner strategies in order to demonstrate their control over the targeted skill(s).

- The separate set of Test-Management Strategies (i.e., strategies for responding meaningfully to the test items and tasks. They include logistic issues such as weighing the importance of responding to different items or tasks, keeping track of the time, and determining where to look for answers ), and a likewise

- The separate set of Test-Wiseness Strategies (i.e., strategies for using knowledge of test formats and other peripheral information to answer test items without going through the expected linguistic and cognitive processes. Examples of test-wiseness strategies that can be used in multiple-choice items, according to Allan, (1992) include: stemoption cues - where matching is possible between the stem and an option, grammatical cues - where only one alternative matches the stem grammatically and item giveaway - where another item already gives away the information).

Test management strategies according to Cohen \& Upton, 2006 call for logical and purposeful response behaviors, are reflective of the underlying competence, and are responsive to the underlying construct being assessed. The test-wiseness strategies, on the other hand, involve the use of textual and/or technical aspects of the test to get the right answers and are not reflective of the underlying competence nor responsive to the underlying construct being assessed. 
Cohen (2007: 95) reviews the scene in test-taking strategies research stating that the last fifteen years have seen a modest but steady increase in the number of studies dealing with test-taking strategies, with a decided increase in the number of related areas included in research focus. Within this body of research, research on test-taking strategies can be grouped into three main bodies of research, namely: 1) testtaking research for the purpose of test validation, 2) relationship between the proficiency level of the respondents and their reported use of strategies in test taking and 3) the research on evaluating the effectiveness of strategy instruction for improving respondents' performance on tests.

The early research on language test-taking strategies focused mostly on test-taking strategies as a necessary evidence for test validation (see Anderson, Bachman and Cohen, 1991; Anderson, Bachman, Perkins and Cohen, 1991; Cohen, 1992, 2007; Gordon, 1987; Nevo, 1989; Tsagari, 1994; Storey, 1997; Abanomey, 2002; Phakiti, 2003; Douglas and Hegelheimerm 2007; Cohen and Upton, 2006). This line of research came in reaction to the critical limitation to correlational and experimental approaches to construct validity which mainly concentrated on the products of the test taking process, the test scores and provided no means for investigating the processes of test-taking themselves (for more on this see Bachman, 1990).

Cohen (2007: 101) concisely summarized the status of this line of research stating that:

"The picture that emerged from the test validation studies is that the field has progressed beyond the days when tests were validated simply by statistical analysis of correct and incorrect response. We have progressed to a point at which we are asking crucial questions about what these tests are actually measuring and taking impressive strides to determine what they actually entail for respondents to arrive at answers to language assessment measures."

Findings from test-taking strategy on how learners arrive at their test responses in different contexts have increasingly been seen to provide insights for test validation, complementing those obtained by correlational and experimental means. Such research have been used in constructing validation studies, providing a new source of data for convergent validation of the construct being assessed. It has also provided insight into how given test methods, formats, and item types may affect learners responses (Tsagari, 1994; Abanomey, 2002; Storey; 1997; Anderson, 1989, 1991) and how these may interact with proficiency (Purpura, 1997, 1998; Yoshizawa, 2002; Phakiti, 2003). 
Finding out ways and strategies to enhance and better students' performance on tests, on the other hand, have become the main interest of researchers, language teachers, and educators. A limited number of studies have been undertaken to investigate the impact of test-taking strategies instruction on test performance (Dreisbach and Keogh, 1982; Amer, 1993; Obah, 1993; Foster and Karn, 1998; Tian, 2000).

An Early study was undertaken by Dreisbach and Keogh, (1982) who examined the impact of training in test-taking strategies on young Mexican-American children performance on a school readiness test. Dreisbach and Keogh trained the experimental group in content-free test-taking strategies, namely, introduction of the test booklet and explanation of test purpose, familiarization with standardized testing vocabulary, practice of three different written responses required in readiness test taking (circle, underline and cross out), emphasis on the importance of practicing good auditory reinforcement of attending drills, and practice in following directions. The control group children were provided comparable time in non-directed paper/crayon activities. The results indicated that trained children performed better than the untrained ones. The researchers concluded that teaching test-taking strategies has a significant impact on the test performance and we should teach children those test strategies.

Another study was carried out by Amer (1993) who tested whether training in test-taking strategies could enhance test performance of eighty-two 7th grade high school students. The experimental group $(n=$ 40) was taught the components of a test-taking strategy: 'to read the instructions carefully', 'to schedule their time appropriately', 'to make use of clue words in the questions', 'to delay answering difficult questions', and 'to review their work in order to check their answers". The results showed that the experimental group outperformed the control group $(n=42)$. The findings suggested that there is a positive relationship between test performance and test-taking strategies. Put differently, the instruction in using test-taking strategies enabled students to better their scores. Amer recommended that there is a need for training EFL classroom teachers to provide instruction in test-taking strategy since one of the reasons of poor performance on EFL tests is perhaps the lack of test-taking strategies and skills.

Similarly, Vattanapath and Jaiprayoon (1999) examined the effectiveness of teaching 22 test-taking strategies for multiple-choice English reading comprehension tests among Thai nursing students as 
well as their attitude towards test-taking strategies. The findings revealed that this training enhanced students' test scores as well as their attitudes towards test-taking strategies instruction. More importantly, participants reported that learning test-taking strategies helped them become more relaxed, more confident and more enthusiastic about sitting for tests.

A further study was carried out by Obah (1993) to probe the effects of teaching one aspect of test-taking strategies, namely, test management strategies on technology-oriented students. The findings indicated a positive relationship between test-taking strategies instruction and how students subsequently managed their time, and improved their test scores. Obah concluded that a crucial aspect of academic success lies in providing learners with a know-how regarding test-taking strategies, especially when it comes to test-time management strategies.

One further study but using a set of 'should do' strategies was undertaken by Foster and Karn (1998) to uncover the effect of teaching test-taking strategies on learners' performance on TOEIC/TOEFL listening and reading comprehension and on their overall English communicative competence. Foster and Karn trained the students on some general and some specific test-taking strategies for the TOEIC/TOEFL tests. The purpose of the general test-taking strategies was to help test-takers manage their time and improve their performance in each section of the two tests. The general strategies included: 'understanding directions to each section of the test before sitting for it', 'avoiding listening to every word', 'leaving no blank answer' and 'guessing from context'. These general strategies help the test-taker to manage their test time effectively. Among the specific test-taking strategies the students were trained on are: eliminating incorrect answers, using time effectively, determining time based on tense (present, past and future) and discourse markers, listening to homonyms.

The study concluded that teaching TOEIC/TOEFL test-taking strategies does in fact improve students' test scores. Test scores of students from four Japanese universities did improve an average of 15.85 percent in elective courses and 10.4 percent in required courses. In addition, students' familiarity with the test improved by 27 percent, their general knowledge of test-taking strategies improved by 21 percent and willingness to guess improved by 14 percent.

The existence of such 'should do' approach encouraged Tian (2000) to probe how the coaching-school training affects Taiwanese students' test-taking behavior on TOEFL reading test. The comparison of high and low scores indicated that the high scorers tended to focus on 
understanding, using the strategies taught by coaching school only as an auxiliary to comprehension, whereas the low scorers tended to focus on word-level strategies, use these strategies in place of comprehension, and follow the coaching school instruction mechanically. Tian recommended teaching general test-taking strategies as an aid to more general comprehension strategies.

In the studies discussed above one can differentiate two different styles of test-taking strategy instruction, namely, 1) the "should do approach" which entails providing guidance in test-management and test-wiseness strategies to help test-takers perform better (Forster \& Karn, 1998; Tian, 2000) and 2) teaching one aspect of test-taking strategies either test-wiseness or test-management strategies (Dreisbach and Keogh, 1982; Obah, 2000; Amer, 1993). None of these studies, however, has looked at their participants' repertoire of test-taking strategies to build up on, nor discussed how the training was carried out, what approach was used in teaching them, nor allowed for ample cued practice opportunity. It is worth mentioning, here, that all these variables were considered in designing the current study. Furthermore, all of these studies looked only for the direction of significance, whereas the current study looks for the direction as well as its power (effect size).

\section{Purpose of the studv:}

The main objective deriving this study was four fold:

- to help adult military EFL trainees learn how to obtain the required score and therefore decrease the number of disenrolled trainees and increase the number of graduates at the Military Language School, Kuwait;

- to bolster adult military EFL trainees confidence about tests and reduce or wade off their test anxiety;

- to empirically probe the effectiveness of the suggested training program in test-taking strategies on enhancing test performance; and

- to empirically probe the effectiveness of the suggested training program on EFL military trainees' knowledge, use and perceived value of test-taking strategies.

\section{Hypotheses of the study:}

- There is no statistically significant differences at .05 level in ALCPT test performance between the mean scores attained by the experimental group trainees (received training in test-taking strategies) and those of the control group trainees (received regular teaching) in the pre and post-testing as measured by the ALCPT test. 
- There is no statistically significant effect size at .05 level in ALCPT test performance between the mean scores attained by the experimental group trainees (received training in test-taking strategies) and those of the control group trainees (received regular teaching) in the pre and post-testing as measured by the ALCPT test.

- There is no statistically significant differences at .05 level in knowledge of test-taking strategies between the mean scores attained by the experimental group trainees (received training in test-taking strategies) and those of the control group trainees (received regular teaching) as measured by the Test-taking Strategy Questionnaire before and after the treatment.

- There is no statistically significant differences at .05 level in use of test-taking strategies between the mean scores attained by the experimental group trainees (received training in test-taking strategies) and those of the control group trainees (received regular teaching) as measured by Test-taking Strategy Questionnaire before and after the treatment.

- There is no statistically significant differences at .05 level in perceived value of strategies used between the mean scores attained by the experimental group trainees (received training in test-taking strategies) and those of the control group trainees (received regular teaching) as measured by the Test-taking Strategy Questionnaire before and after the treatment.

- There is no statistically significant effect size at .05 level in knowledge of test-taking strategies between the mean scores attained by the experimental group trainees (received training in test-taking strategies) and those of the control group trainees (received regular teaching) in the pre and post-testing as measured by the Test-taking Strategy Questionnaire.

- There is no statistically significant effect size at .05 level in use of test-taking strategies between the mean scores attained by the experimental group trainees (received training in test-taking strategies) and those of the control group trainees (received regular teaching) in the pre and post-testing as measured by the Test-taking Strategy Questionnaire.

- There is no statistically significant effect size at .05 level in perceived value of test-taking strategies between the mean scores attained by the experimental group trainees (received training in test-taking strategies) and those of the control group trainees (received regular teaching) in the pre and post-testing as measured by the Test-taking Strategy Questionnaire. 


\section{Significance of the study:}

- The study adds to the limited database in test-taking strategy instruction that still in its infancy especially in the Arab world and considers avoiding some limitation in the studies reported in this area.

- The study provides those who are in charge of EFL teachers preparations programs with a systematically designed programme in test-taking strategies that may help raise their pre-service teachers' awareness about test-taking strategy and how to teach them.

- The study provides EFL instructors with a systematically designed programme in test-taking strategies that may help EFL trainees better their performance and scores on tests in general and ALCPT test in particular.

- The study sets an example for future research in test-taking strategy instruction in terms of the potential of using such strategies on enhancing test performance.

\section{Method and procedures Subjects :}

The subjects participated in the current study were 50 EFL Military trainees who studied at the Language School, MOD, Kuwait during the academic year 2008. The participants were all native male Arabic speakers who were at a high elementary level of proficiency. Prior to the experiment, the 50 trainees were pretested using form 68 of the ALCPT test and then assigned to one of the two groups, namely the experimental group $($ no $=27)$ and the control group $($ no $=23)$. The control groups received the same language input, same number of lessons and hours, even the same practice test CD but with no instruction in test-taking strategies. The practice test $C d$ was used mainly to expose and familiarize trainees with past tests by answering questions. Furthermore, and to ensure compatibility of the groups the two were pretested at the same time in the knowledge, use and perceived value of test-taking strategies (Test-taking strategy questionnaire) and test performance (ALCPT). The pretest results of t-test for the experimental and control groups in both measures were insignificant, which mean the variances are equal and the two groups started at approximately the same level (see table 2 below). The experimental group received the suggested training program of test-taking strategies (see figure 1 below) whereas the control group received regular teaching classes. The training lasted for 12 weeks, twice a week totaling 24 sessions. By the end of the 12 weeks, the two groups were post-tested using the same form of the ALCPT. 


\section{Instruments :}

The study used two main instruments, namely, the ALCPT Test and the Test-taking Strategy Questionnaire. Detailed descriptions of the instruments used in this study are given below.

\section{ALCPT test :}

The American Language Course Placement Test (ALCPT) is a standardized, valid and reliable proficiency test of listening and reading comprehension in English designed by DLEELC (see Cheng et al., 2004). The test can be used to screen students for readiness to sit for the English Comprehension Level (ECL) test, the official version of the ALCPT used by the United States government to measure the English Language Proficiency for non-native English speakers who are candidates for US military training. Furthermore, the ALCPT test is used to determine students' progress through the ALC material. Once a student is placed, the chart (appendix 1) can be used to check for satisfaction. Students are expected to obtain from 3 to 5 marks at each book. There are 35 alternate forms available of the ALCPT. Each form of the 35 is of approximately the same difficulty and reliability level (reliability coefficient $=.94$ ) and each consists of a listening part and a reading part. Both parts of the test contain four-option multiple-choice items that test some aspects of grammar, vocabulary, and reading. All available ALCPT forms contain 100 questions and is fully computerized. Part I (66 items) of the ALCPT is presented aurally. The student listens to an aural input in English in the form of questions, statements, and dialogs on the $C D$ and click on the correct answer on the computer. Part II (34 questions) of the ALCPT consists of reading items and is designed to test the ability of the student to understand written material.

Form 68 of the ALCPT was used as a pre-test at the beginning of the programme for both groups. Following the instruction period, the same form was administered as the post-test to assess the change, if any, in overall linguistic proficiency after the 12 weeks experimental period. Any score gained (i.e., the difference between the pre and post-test scores) could be interpreted as a measure of improvement in overall language proficiency as measured by the ALCPT.

\section{The reliability of the ALCPT test :}

To ensure that the test was reliable to the sample of the study, the researcher calculated the test reliability using test-retest method. The reliability coefficient computed for the test was 94.4 which indicates that the test is of high reliability making it ready for administration (appendix 2). 


\section{Test-Taking Strategy Questionnaire :}

The Test-Taking Strategy Questionnaire was designed to collect information about:

- trainees' knowledge of test-taking strategies,

- their use of such strategies, and

- their perception of the value of using these strategies.

$A$ set of focal and relevant to the nature of the ALCPT test-taking strategies was identified based on the related literature. Those strategies were selected in the light of the following selection guiding criteria:

- expanding not replacing trainees' test-taking strategies,

- selecting strategies that enable trainees to experience the immediate pay-off,

- teaching test-taking strategies with the widest possible application.

These strategies were operationalized in simple statements (see below) followed by 3 main levels, namely, Knowledge (I know this strategy), Use (I use this strategy) and value (This strategy helped me). The Test- taking Strategies Questionnaire (appendix 3) was administered to both groups before and after the treatment to assess any improvement in knowledge of test-taking strategies, their use as well as any change of the perceived value of test-taking strategy use.

Table 1: Sample of Test-taking Strategy Questionnaire

\begin{tabular}{|c|c|c|c|c|c|c|c|c|c|c|}
\hline Strateg & \multicolumn{3}{|c|}{ I know this strategy } & \multicolumn{3}{|c|}{ I use this strategy } & \multicolumn{4}{|c|}{ This strategy helped me } \\
\hline & Yes & $\begin{array}{l}\text { Not } \\
\text { Sure }\end{array}$ & No & Always & Sometimes & Rarely & Never & $\begin{array}{c}\text { Not } \\
\text { At } \\
\text { All }\end{array}$ & $\overline{\text { A little }}$ & Alot \\
\hline & 3 & 2 & 1 & 3 & 2 & 1 & $\overline{1}$ & 2 & 3 & 4 \\
\hline $\begin{array}{l}\text { I gather } \\
\text { as much } \\
\text { informati } \\
\text { on as } \\
\text { possible } \\
\text { by } \\
\text { studying } \\
\text { the } \\
\text { answer } \\
\text { choices } \\
\text { before } \\
\text { listening/ } \\
\text { reading } \\
\text { to the } \\
\text { question } \\
\text { (Previewi } \\
\text { ng) }\end{array}$ & & & & & & & & & & \\
\hline
\end{tabular}




\section{Validity of the test-taking strategy questionnaire:}

To calculate the validity of the questionnaire, the researcher used the correlation between trainees score on the different cores of the testtaking strategy questionnaire and the total scores from the respondents. Table 2 below shows the correlation between trainees' scores on the different cores of the questionnaire and the overall scores.

Table 2: Internal Consistency Indices

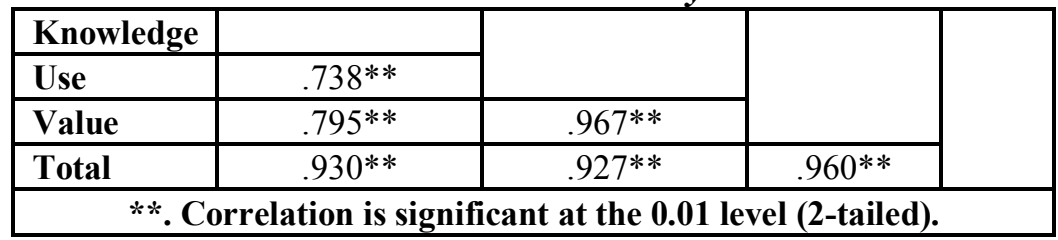

The table shows that all the correlations between the total scores and the scores on each core is significant at 0.01 level, let alone the fact that their values are high. This indicates a high internal consistency of the test-taking strategy questionnaire

\section{The reliability of the test-taking strategy questionnaire:}

The reliability of the test-taking strategy questionnaire was calculated by Alpha Cronbach in SPSS 20. The reliability coefficient was 0.98 which indicates that the questionnaire is of high reliability making it ready for administration.

\section{Training program:}

The treatment material comprised the training programme which incorporated a-24 training sessions. Each session consisted of

- a strategy presentation session

- a consolidation unit

- extracts from the practice CD test

- worksheets/handouts/factsheet files

- practice on all strategies presented

The program used in this study mainly encompassed two phases, namely, training on general test-wiseness and time management strategies and language learning strategies. Figure 1 below shows the components and phases of the suggested programme that the experimental group received and which included test-wiseness strategies, test-management strategies and learning strategies as well as the nature of the approach used in teaching those strategies. The purpose of phase one was threefold:

- raising trainees awareness about the nature of the ALCPT, its formats, and how the test is structured, 
- uncovering trainees' stored knowledge about test-taking strategies, and

- empowering trainees with some test-wiseness and test-management strategies.

This Phase started with giving an overview of the ALCPT in which the researcher discussed with the trainees the purpose of the test, its structure, number of sections, questions, directions of each section, test formats, types of questions, skills assessed and allocated time. Then, the trainees' stored knowledge of test-taking strategies was revisited. In doing so, the researcher discussed with the trainees what test-wiseness and test-management strategies mean, are they natured or nurtured. After that, the researcher highlighted some test-wiseness (stem-option cues - where matching is possible between the stem and an option, grammatical cues - where only one alternative matches the stem grammatically and item giveaway - where another item already gives away the information) and test management strategies (e.g., understanding directions to each section, avoid listening to every word, listening to the gist, leaving no blank answer, stop worrying about unknown words, using time wisely, eliminating incorrect answers while hearing them, eliminating any options that obviously cannot be correct, etc.).

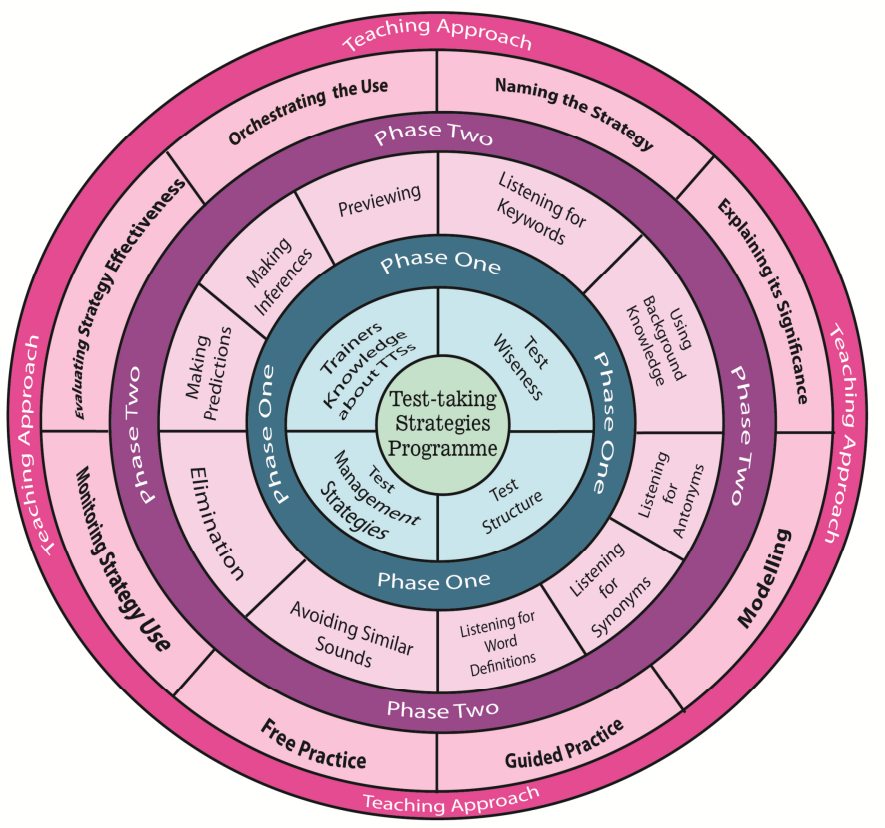

Figure 1: Components and Phases of the 
Phase two (see the figure above) focused on teaching the learning strategies relevant to the ALCPT (e.g., previewing answers, listening for key words and discourse markers, using background knowledge, elimination, avoiding similar sounds, making inferences, focusing on the second speaker, making predictions, listening for word definition and listening for synonyms and antonyms). The purpose of this second phase was to:

- empower trainees with the needed skills and strategies to sit for the ALCPT test;

- expose trainees to as many test-taking strategies as possible in both discrete and integrated fashion;

- practise using those strategies in a discrete and integrated fashion;

- train the trainees on how to orchestrate those strategies in actual tests;

- expose students to past test papers and practice tests (Practice Test $C D)$.

The training program lasted for 12 weeks, twice a week totaling 24 sessions. All the examples for training were taken from a Practice Test $C D$ which has got 35 practice tests; each test of 100 items. To deliver the programme, the researcher followed the informed approach (for more on this approach see Cohen, 1998, 1999; Oxford, 1990; which entails the following steps:

- Naming, presenting and explaining the strategy significance;

- Modeling the strategy;

- Guided practice;

- Checking and evaluating the strategy effectiveness;

- Free practice using the strategy in discrete and integrative fashion;

- Orchestrating the use of strategies taught.

An example depicting how the teaching approach used in this study was put into action for teaching one of the strategies - previewing - is demonstrated in the table below.

\begin{tabular}{|c|c|c|c|c|c|c|}
\hline STRATEGY & \multicolumn{3}{|c|}{ COMPONENTS/STEPS } & MATERIAL & TRAINER'S ROLE & $\begin{array}{c}\text { TRAINEE'S } \\
\text { ROLE }\end{array}$ \\
\hline \multirow{2}{*}{ 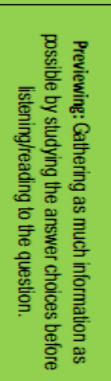 } & \multirow{2}{*}{ 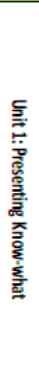 } & $\begin{array}{l}\text { Presenting the } \\
\text { strategy: giving } \\
\text { an overview of } \\
\text { the strategy } \\
\text { (Know- what) }\end{array}$ & $\begin{array}{l}\text { - Naming the strategy } \\
\text { - What does it mean } \\
\text { - When/why to use it } \\
\text { - How to use it }\end{array}$ & $\begin{array}{l}\text { Extracts from } \\
\text { the Practice } \\
\text { CD. } \\
\text { Audio Clips } \\
\text { Lesson Plans } \\
\text { Handouts }\end{array}$ & $\begin{array}{l}\text { - Teacher-led small- } \\
\text { group/whole class } \\
\quad \text { discussion } \\
\text { - Brainstorming-led } \\
\text { discussion } \\
\text { - Coach } \\
\text { - Trainer } \\
\text { - Facilitator } \\
\end{array}$ & $\begin{array}{l}\text { Noting } \\
\text { Discussing } \\
\text { Sharing } \\
\text { ideas }\end{array}$ \\
\hline & & $\begin{array}{l}\text { Modelling the } \\
\text { strategy: } \\
\text { demonstrating } \\
\text { how it works in } \\
\text { action by } \\
\text { thinking-aloud } \\
\text { while applying } \\
\text { the strategy } \\
\text { (know- how) }\end{array}$ & $\begin{array}{l}\text { How does an expert } \\
\text { (trainer) use } \\
\text { previewing? } \\
\text { How does he } \\
\text { approach the test } \\
\text { questions? } \\
\text { What clues does he } \\
\text { attend to/ignore? } \\
\text { How does he budget } \\
\text { his time? }\end{array}$ & $\begin{array}{l}\text { Extracts from } \\
\text { the Practice } \\
\text { CD. } \\
\text { Audio Clips } \\
\text { Lesson Plans } \\
\text { Handouts }\end{array}$ & $\begin{array}{l}\text { Apprenticeship } \\
\text { approach: the } \\
\text { apprentice gradually } \\
\text { takes over the } \\
\text { responsibility. } \\
\text { - Involves trainees by } \\
\text { asking questions } \\
\text { - Demonstrating how } \\
\text { to use time for } \\
\text { directions for } \\
\text { previewing. - Coach }\end{array}$ & $\begin{array}{c}\text { Active } \\
\text { participant } \\
\text { Applying }\end{array}$ \\
\hline
\end{tabular}


Number 28, Part 3, August, 2012

\begin{tabular}{|c|c|c|c|c|c|}
\hline & $\begin{array}{l}\text { Practice: } \\
\text { providing } \\
\text { opportunities to } \\
\text { practice active } \\
\text { application of } \\
\text { the strategy to } \\
\text { test questions }\end{array}$ & $\begin{array}{l}\text { - Provided } \\
\text { guided/graded } \\
\text { application of strategy } \\
\text { use till trainees } \\
\text { become able to } \\
\text { regulate use of the } \\
\text { strategy on their own. } \\
\text { - Applying the } \\
\text { strategy to actual test } \\
\text { items. }\end{array}$ & $\begin{array}{l}\text { Extracts from } \\
\text { the Practice } \\
\text { CD. } \\
\text { Audio Clips } \\
\text { Lesson Plans } \\
\text { Handouts }\end{array}$ & $\begin{array}{l}\text { - Nurture trainees in } \\
\text { their application of } \\
\text { the strategy. } \\
\text { - Awarding words of } \\
\text { praise when the } \\
\text { strategy used } \\
\text { successfully } \\
\text {-Reminding the } \\
\text { trainees of the clues } \\
\text { when possible. }\end{array}$ & $\begin{array}{c}\text { Active } \\
\text { participant } \\
\text { Applying }\end{array}$ \\
\hline
\end{tabular}

\section{Data Analysis}

\begin{tabular}{|c|c|c|c|c|c|c|}
\hline STRATEGY & \multicolumn{3}{|c|}{ COMPONENTS/STEPS } & MATERIAL & \multirow[b]{2}{*}{$\begin{array}{l}\text { TRAINER'S ROLE } \\
\text { Nurture trainees in } \\
\text { their application of } \\
\text { the strategy. } \\
\text { - Awarding words of } \\
\text { praise when the } \\
\text { strategy used } \\
\text { successfully } \\
\text {-Reminding the } \\
\text { trainees of the clues } \\
\text { when possible. }\end{array}$} & \multirow{2}{*}{$\begin{array}{c}\text { TRAINEE'S } \\
\text { ROLE } \\
\text { Active } \\
\text { participant } \\
\text { Applying } \\
\text { Assessor }\end{array}$} \\
\hline 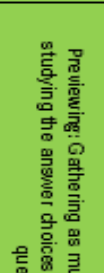 & 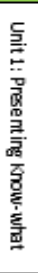 & $\begin{array}{l}\text { Evaluating } \\
\text { Strategy } \\
\text { Effectiveness: } \\
\text { getting trainees } \\
\text { to evaluate the } \\
\text { effectiveness of } \\
\text { the strategy and } \\
\text { difficulties that } \\
\text { arose from the } \\
\text { strategy use and } \\
\text { reasons for such } \\
\text { difficulties }\end{array}$ & $\begin{array}{l}\text { Does the strategy } \\
\text { work? } \\
\text { Is the strategy } \\
\text { effective? } \\
\text { How does it help }\end{array}$ & $\begin{array}{l}\text { Extracts from the } \\
\text { Practice CD. } \\
\text { Audio Clips } \\
\text { Lesson Plans } \\
\text { Handouts }\end{array}$ & & \\
\hline 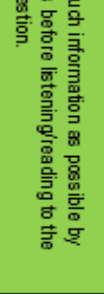 & 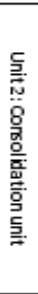 & $\begin{array}{l}\text { Every two } \\
\text { strategies } \\
\text { presented were } \\
\text { followed by a } \\
\text { consolidation } \\
\text { unit so that } \\
\text { trainees would } \\
\text { feel more } \\
\text { comfortable and } \\
\text { confident with } \\
\text { strategy use. }\end{array}$ & $\begin{array}{l}\text { The consolidation } \\
\text { unit aimed at } \\
\text { giving trainees } \\
\text { more } \\
\text { opportunities for } \\
\text { the active } \\
\text { application of the } \\
\text { two strategies } \\
\text { presented and } \\
\text { help them } \\
\text { combine more } \\
\text { than one strategy } \\
\text { at a time. }\end{array}$ & $\begin{array}{l}\text { Extracts from the } \\
\text { Practice CD. } \\
\text { Audio Clips } \\
\text { Lesson Plans } \\
\text { Handouts }\end{array}$ & $\begin{array}{l}\text { Nurture trainees in } \\
\text { their application of } \\
\text { the strategy. } \\
\text { - Awarding words of } \\
\text { praise when the } \\
\text { strategy used } \\
\text { successfully } \\
\text {-Reminding the } \\
\text { trainees of the clues } \\
\text { when possible. }\end{array}$ & $\begin{array}{c}\text { Active } \\
\text { participant } \\
\text { Applying } \\
\text { Assessor }\end{array}$ \\
\hline
\end{tabular}

To answer the study questions and test the hypotheses, the researcher made use of the following statistical analyses:

- Descriptive statistics: the calculation of the raw mean scores for the two groups of the study in the ALCPT test and the Test-taking Strategy Questionnaire;

- T-test to find out the effect of the suggested programme in test-taking strategies on the ALCPT performance (to find the differences between the two groups in $A L C P T)$;

- Eta Squared to find the effect size of the suggested programme in testtaking strategies on the ALCPT performance (how big the effect was);

- T-test to find out the effect of the suggested programme in test-taking strategies on the knowledge of test-taking strategies, use and perceived value (to find the differences between the two groups in test-taking strategy knowledge use and perceived value); and

- Eta Squared to find the effect size of the suggested programme in testtaking strategies on the knowledge of test-taking strategies, use and perceived value (how big the effect was). 


\section{Results:}

Effectiveness of the suggested training programme on the ALCPT Performance:

The raw mean scores of the two groups of the study in the ALCPT test before and after the treatment are graphically represented in figure 2 below. The graph demonstrated that the two groups almost started at the same level as they attained nearly the same scores, the mean score in the control group was even higher given the number of each group. However, after the treatment, the differences between the two groups are distinctively clear. An increase, on the one hand, in the mean scores of the control group (received regular teaching) can be noticed. The experimental group, on the other hand, improved remarkably in the ALCPT. To sum up as far as descriptive statistics show, there was a noticeable improvement in the experimental group and some improvement in the control group.

Figure 2: Raw Mens of the experimental and control groups in ALCPT before and after the treatment

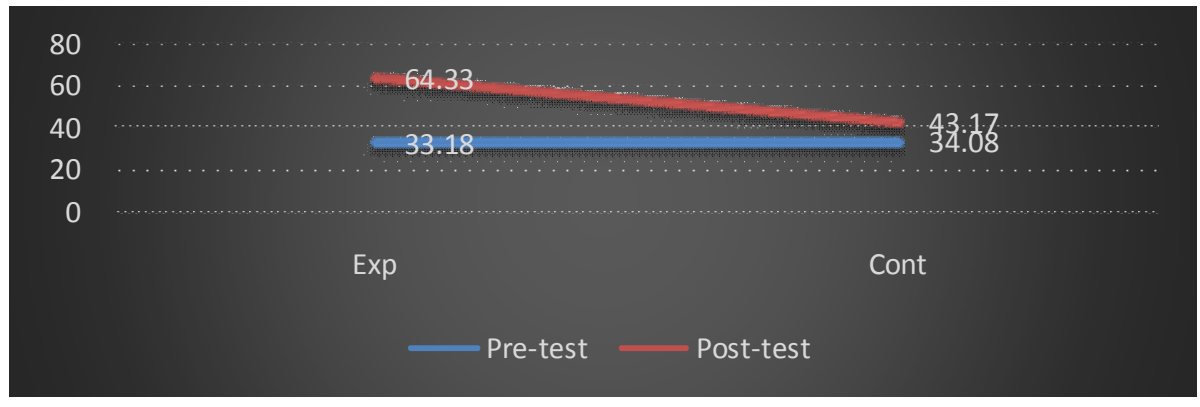

To find the differences in ALCPT performance between the experimental and control group students, t-test was used (see table 3 below).

Table 3: Pretest Results of t-Test for the Experimental and Control Groups in ALCPT

\begin{tabular}{|l|l|l|l|l|}
\hline Experimental & 27 & 33.1852 & 4.85194 & 637 \\
\hline Control & 23 & 34.0870 & 5.14263 & \\
\hline
\end{tabular}

Inspection of the above table reveals that there is no significant difference in the pretest between the experimental and control groups in the ALCPT test. This means the two variances are approximately equal and the pretests in the two groups are approximately equal.

Table 4: Posttest Results of t-Test for the Experimental and Control Groups in ALCPT

\begin{tabular}{|l|l|l|l|l|}
\hline Experimental & 27 & 64.3333 & 7.40582 & $10.977^{*}$ \\
\hline Control & 23 & 43.1739 & 5.989778 & \\
\hline
\end{tabular}


Table 4 above indicates that there is a significant difference at .01 level in the posttest between the mean scores of the experimental and control groups in the ALCPT in favor of the experimental group. This means that hypothesis no. 1 stating: "There is no statistically significant differences at .05 level in ALCPT test performance between the mean scores attained by the experimental group trainees (received training in test-taking strategies) and those of the control group trainees (received regular teaching) in the pre and post-testing as measured by the ALCPT test" was rejected. Put differently the suggested programme in testtaking strategies enhanced trainees' scores and performance on the ALCPT test.

Effect size of the suggested training programme on the ALCPT Performance:

The researcher was interested in uncovering the effect size; how much variance in the dependent variable (ALCPT test performance) was a result of the independent variable (suggested training programme in test-taking strategy). Since t-test does only provide the statistical significance and its direction, the researcher used Eta Squared $\left(\eta^{2}\right)-a$ measure that describes the proportion of variance associated with or accounted for by each of the main effect, interaction and error in an ANOVA study (see Thompson, 2006:317). Put simply, it looks at how much variance in the dependent variable was a result of the independent variable. The researcher calculated $\eta^{2}$ using SPSS (20). Table 5 below shows the value of $\left(\eta^{2}\right)$ in the ALCPT test performance.

\begin{tabular}{|c|c|c|}
\hline \multicolumn{3}{|c|}{ Table 5: Eta Squared results of the treatment on } \\
ALCPT test performance \\
\hline & Eta & Eta Squared \\
\hline performance $*$ & .742 & .551 \\
\hline
\end{tabular}

The table indicates that there is a large effect size (.551) to the effect of the suggested training program in test-taking strategies on ALCPT test performance. This means that hypothesis no. 2 stating: "There is no statistically significant effect size at 05 level in ALCPT test performance between the mean scores attained by the experimental group trainees (received training in test-taking strategies) and those of the control group trainees (received regular teaching) in the pre and post-testing as measured by the ALCPT" was rejected and in effect, the change in the trainees' performance on the ALCPT can be, by large, attributed to the effect of the suggested training programme in test-taking strategies. 


\section{Effects of the suggested training programme on the test-taking strategy} knowledge, use and value:

Table 6 below shows the raw mean scores of the two groups of the study before and after the treatment in the three areas addressed in the test-taking strategy questionnaire, namely, a) knowledge of test-taking strategies, use of test-taking strategies and the perceived value of testtaking strategies.

Table 6: Raw mean scores of the study groups in the pre and post testtaking strategies questionnaire

\begin{tabular}{|l|c|c|c|c|c|c|}
\hline & Before & After & Before & After & Before & After \\
\hline Experimental & 32.22 & 81.00 & 28.25 & 42.18 & 26.22 & 54.22 \\
\hline Control & 28.86 & 31.26 & 25.21 & 25.95 & 21.34 & 21.34 \\
\hline
\end{tabular}

The graph in figure 3 below illustrates the differences between the two groups of the study in the three areas addressed in the test-taking strategy questionnaire. The graphs convincingly demonstrate that the two groups of the study showed a very similar pattern of results. Generally speaking, the two groups started almost at the same point before the experiment. After the treatment, the experimental group that received training in test-taking strategies showed a remarkable change in the three areas, whereas the control group remained at almost the same level.

More specifically, and looking at the knowledge level, as figure 3 shows, it is obviously clear that there is a remarkable change in the level of knowledge of test-taking strategies in case of the trainees in the experimental group before (mean score $=32.22$ ) and after the treatment (mean score $=81.00)$, which is self-explanatory at that level.

Similar results were obtained in the second area of the questionnaire, test-taking strategy use. Again, trainees in the experimental group demonstrated a significant leap after the treatment (mean score $=42.12$ ) in terms of reported test-taking strategy use. Finally, the same pattern of results was recurrent regarding the perceived value of using test-taking strategies; the mean scores of the trainees in the experimental group increased sharply from 26.22 before the treatment to 54.22 after the treatment.

This is perhaps an expected results due to the treatment those trainees received in which an array of test-taking strategies was explicitly and overtly introduced, named, modelled, practiced extensively at the discrete and integrated level and trainees were encouraged to use these test-taking strategies independently. More importantly, experiencing the potential those strategies have and their pay-off in terms of better test 
performance, the trainees tended to rely on those strategies more. All these factors added to the high level of appreciation trainees in the experimental group developed regarding the use and value of test-taking strategies.

To find the differences between the experimental and control group students in test-taking strategy knowledge, strategy use and perceived value of such strategies, $t$-test was used (see table 7 below).

Table 7: Pretest Results of t-Test for the Experimental and Control Groups in Test-taking strategy knowledge, use and value

\begin{tabular}{|c|c|c|c|c|c|}
\hline Knowledge & Ex. & 27 & 32.22 & 10.08 & \multirow[b]{2}{*}{1.22} \\
\hline & Cont. & 23 & 28.86 & 9.07 & \\
\hline Use & Ex. & 27 & 28.25 & 9.77 & \multirow[b]{2}{*}{1.20} \\
\hline & Cont. & 23 & 25.21 & 7.81 & \\
\hline Value & Ex. & 27 & 26.22 & 16.39 & \multirow[b]{2}{*}{1.35} \\
\hline & Cont. & 23 & 21.34 & 8.19 & \\
\hline
\end{tabular}

Inspection of the above table reveals that there is no significant difference in the pretest between the experimental and control groups in the three areas addressed in the questionnaire, namely, knowledge of test-taking strategies, use and their perceived value. This means the variances are approximately equal and the pretests in the two groups are approximately equal.

Table 8: Posttest Results of t-Test for the Experimental and Control

Groups in in Test-taking strategy knowledge, use and value

\begin{tabular}{|c|c|c|c|c|c|}
\hline & $\begin{array}{c}\text { Ex. } \\
\text { Knowledge }\end{array}$ & 27 & 81.00 & .000 & \multirow[t]{2}{*}{24.99} \\
\hline Knowledge & Cont. & 23 & 31.26 & 9.54 & \\
\hline & Ex. & 27 & 42.18 & 8.54 & \multirow[b]{2}{*}{6.50} \\
\hline Use & Cont. & 23 & 25.95 & 8.66 & \\
\hline & Ex. & 27 & 54.22 & 8.66 & \multirow[b]{2}{*}{10.40} \\
\hline Value & Cont. & 23 & 21.34 & 8.19 & \\
\hline
\end{tabular}

Table 8 above indicates that there is a significant difference at .01 level in the posttest between the experimental and control groups in the test-taking strategy knowledge, use and value in favor of the experimental group. This means hypotheses 2, 3 and 4 "There is no statistically significant differences at .05 level in $2 \mathrm{knowledge,} \mathrm{3use} \mathrm{and}$ 4perceived value of test-taking strategies between the mean scores attained by the experimental group trainees (received training in testtaking strategies) and those of the control group trainees (received regular teaching) as measured by the strategy questionnaire before and after the treatment" were rejected. Put differently the suggested programme enhanced trainees knowledge of test-taking strategies, their use as well as their perceived value of such strategy use. 
Effect size of the suggested training programme on knowledge, use and perceived value of test-talking strategies:

Again, Eta squared $(\eta)$ was also used to find the effectiveness of the treatment (the suggested training programme in test-taking strategies) on knowledge, use and perceived value of test-taking strategies. Table 9 below shows the value of $\left(\eta^{-}\right)$in knowledge of test-taking strategies (.924), use of test-taking strategies (.366) and the perceived value of using such strategies (.480).

Table 9: Eta Squared results of the treatment on knowledge, use and perceived value of test-taking strategies

\begin{tabular}{|l|c|r|}
\hline Cores & Eta & Eta Squared \\
\hline Knowledge & .961 & .924 \\
\hline Use & .605 & .366 \\
\hline Value & .693 & .480 \\
\hline
\end{tabular}

This means that the effect size is very large and $92.4 \%$ of the change in the trainees' knowledge of test-taking strategies, 36.6, of the change in the trainees' use of test-taking strategies and 48\% of the change in the trainees' perceived value of test-taking strategies can be attributed to the effect of the suggested training programme. This means hypothesis no. 6 , 7 and 3 stating that: "There is no statistically significant effect size at .05 level in 6knowledge, 7use and 8perceived value of test-taking strategies between the mean scores attained by the experimental group trainees (received training in test-taking strategies) and those of the control group trainees (received regular teaching) in the pre and posttesting as measured by the test-taking strategy questionnaire, was rejected.

\section{Discussion :}

The driving aim of the current study was to seek ways of helping adult EFL military trainees obtain the required score on ALCPT and therefore decrease the number of disenrolled trainees and increase the number of graduates at the MLS, Kuwait. The study sought to examine the effectiveness of a suggested training program in test-taking strategies on enhancing ALCPT performance and strategy knowledge, use and value among adult EFL military trainees. A training programme in test-taking strategy was designed and delivered for 24 hours. The results of the quantitative data analysis indicated that test-taking strategies instruction was more effective in enhancing adult EFL military trainees' performance on the ALCPT than the regular teaching program. Furthermore, the suggested programme in test-taking strategies enhanced trainees' knowledge, use as well as perceived value of testtaking strategy use.

Findings of the current study are consistent with those obtained by Dreisbach \& Keogh (1981) as well as Foster and Karn (1998), 
suggesting that knowing basic facts about the test and being familiar with its structure in addition to training on test-taking strategies did have an enhancing effect on students' performance. Similarly, the findings are in agreement with those of Amer (1993) and Obah (1993) regarding the positive relationship between test-taking strategy instruction and test performance. Both highlighted that there is a need to have room for test-taking strategy instruction in our classrooms and that better test performance is dependent upon providing learners with a know-how regarding test-taking strategies and in particular testmanagement strategies (see Foster and Karn, 1998).

A plausible interpretation of this finding can be attributed to the programme with its two phases. Phase one, in effect, built trainees' awareness about the ALCPT test, what it covers, how many questions are there, what formats the questions are in, what questions look like, directions and what is being asked, and how answers are scored. Knowing the basic facts about the ALCPT might have helped cure one of the main causes of test anxiety, namely, being unfamiliar with the test. Trainees no longer have to worry about listening to or reading the instructions, what is more is the fact that they fully understand exactly what is going to be on the target exam. Phase one of the programme familiarized trainees with the ALCPT in terms of the structure, timing and instruction set - so that these became second nature. They became, by the end of this phase, ready to take the ALCPT with full knowledge of all sections and without the need to listen to or read directions. Not only does this ultimately help test-takers manage and save their time on the actual test, but they are instilled with confidence and surprises during the actual test are minimized.

Following phase one, trainees in the experimental group were exposed to and practiced a wide range of test-taking strategies that allowed them to handle the test demands efficiently and with confidence at both the discrete and integrative levels during the second phase of the programme, which was another possible interpretation for the better performance of trainees. Discrete test-taking strategies training provided trainees with the needed tools to deal with the ALCPT strategically and more effectively. They were informed of and trained in how to deal with the test demands strategically, watched strategies being modeled and had considerable guided and free practice with actual past tests.

At the discrete level previewing, for example, helped trainees gather as much information as possible by studying the choices before 
reading/listening to the question. Given the fact that trainees are aware of the directions of the ALCPT sections, they became steps ahead which gave them time to preview. Previewing helped them activate the relevant schemata (i.e., content/formal), minimize the alternatives, listen selectively and manage their time wisely and in turn be in a better position to deal with the input strategically. Using stress knowledge (word/sentence/shifting/contrastive stress) to identify accurately the most important information carrier unit or what is referred to as to listening to keywords was a further strategy that helped trainees, at the discrete level, to focus on specific items, listen for the gist and avoid memory overload. Listening for key or stressed words helped trainees avoid word-by-word listening and to be after the gist; general understanding is sufficient and more realistic. Using background knowledge, relating the known/familiar information to the unknown/unfamiliar to figure out the intended meaning of the speaker/writer, is one more strategy that helped trainees identify relevant from irrelevant information and make associations between new information and previously acquired knowledge. Furthermore, it helped trainees use new information to clarify or modify their prior knowledge as well as personalize it. Process of elimination is one more strategy which helped trainees identify and eliminate obviously wrong and illogical answers. The underlining assumption behind this strategy is that since there are more wrong answers than correct ones, trainees are taught not to look for the correct answer; hence wrong answers are easier to find. Such a strategy helped trainees isolate and eliminate grammar and structure inconsistencies in questions and answers as well as eliminate incorrect answers to Whquestions. Word analysis (deconstruction) or guessing the meaning of unfamiliar/unknown words by breaking it into its parts (i.e., prefix + root + suffix), was one more strategy that helped trainees deal with reading and listening more effectively. Avoiding similar sounds, an additional strategy, enabled the trainees not to be misled by the words which might have the same sound (e.g., homophones and homographs) but different spelling and meaning. Often incorrect answers are answers that contain words with similar sounds but very different meanings from what is heard in the aural input. Quite often we do not hear the exact words given in the questions, instead you hear a synonym or an opposite but not the same wording.

Access to appropriate strategies at the discrete level was an important element, being able to use these strategies was another crucial element, but being able to orchestrate the use of these test-taking strategies was more crucial and cannot happen without confidence which came with practice and achieving success at the discrete level. The suggested programme provided trainees with ample opportunity for 
guided and free practice at the discrete and integrative level. During the guided practice stage, the researcher used to nurture trainees in their application of test-taking strategies taught, giving them reminders of the clues, be they contextual, linguistics, or paralinguistic, they should be looking for and pointing out when a given strategy was used successfully. In addition the free practice stage gave the trainees the opportunity to use combination of strategies, rather than relying on one or two preferable discrete strategies.

To sum up knowing the basic facts about the test helped trainees become aware that success or failure in ALCPT is more dependent on their effort and the test-taking strategies they use rather than on their innate ability or mere luck. This in turn helped prepare the trainees for the active and interactive role they were expected to play in the programme. Having a repertoire of effective test-taking strategies at hand gave the students the motive to survive and take the risk. In effect, it helped build and boost trainees' confidence to break with familiar patterns and embark on a new way of working, which in turn helped them use their memory resources more effectively. These factors helped maintain trainees' high level motivation that helped them work hard, preserve in face of difficulties and find satisfaction in the accomplishment of a learning task.

\section{Implications :}

The overall findings of the study have pedagogical and future research implications. A general implication of the findings obtained in this study is that it added to the growing body of research in test-taking strategies instruction which maintain that test-taking strategies do have an enhancing effect on test performance and scores. Informed and explicit test-taking strategy instruction, which calls for test-taking strategies to be named, modelled, and provides substantial guided and free practice at the discrete and integrated level, should be perceived as a crucial component in curriculum for students to better their scores on tests. With this in mind, one of the main responsibilities of language teachers is to train their learners in using effective test-taking strategies suitable to the test formats.

A further equally important and closely related implication is that for test-taking strategies to be effective and bring about its desired effect, we should start teaching such strategies early, infuse test-taking strategy instruction into the curriculum. Closely related is the fact that preservice teacher training programs should prepare teachers so as to be able to teach test-taking strategies and help their students enhance their 
knowledge and use of test-taking strategies to better their score. In doing so, teachers need to visit their students stored knowledge about test and testing as well as their existing repertoire of test-taking strategies and strengthen them if effective as well as introduce and model new alternatives and additional strategies.

The study demonstrated that when students are familiar with the test, they approach the testing situation more relaxed, enjoy full capacity of memory resources and be in better position to make informed decisions and manage their time effectively. An implication of this is that knowing basic facts about the test, its formats and structure is a central component to test-taking strategy instruction. Therefore, any programme in test-taking strategies should start with an overview of the test, which is a perquisite for making informed decision about the testing situation and selecting the appropriate and relevant strategy to the test demands.

\section{Recommendations for future research :}

- The present investigation has raised a number of questions, which needs further research.

- Results of this study need to be validated in different context with different language learners. If future research provides further support for the findings, the implications for test-taking strategy instruction would be significant.

- The current study was interested in the effectiveness of test-taking strategy instruction on ALCPT which is an MCQs English Comprehension Test, a further study could probe the effect of testtaking strategy instruction on other test formats (e.g., cloze-tests, gapfilling, essay writing, and matching).

- The current study was carried out with EFL Adult military trainees in Kuwait studying English for general purposes, further studies need to target learners from different backgrounds, in different fields of study and lor from different age level.

- The data gathered in the current study was collected from learners only, future research should be extended to data elicited from instructors themselves.

- Test-taking strategy use depends on a number of factors such as proficiency level, learning styles, gender, motivation and attitude. Further research can investigate test-taking strategies in relation to some of these factors.

\section{Conclusions}

The study demonstrated that explicit test-taking strategy instruction which cater for modeling, and provide ample opportunity for guided and free practice at both discrete and integrated levels resulted in enhancing trainees' test performance as well as their knowledge, use and perceived value of test taking strategies. The implication of this is that time devoted 
to test-taking strategy instruction, on the contrary to some arguments that devoting time to test-taking strategy should be devoted to building learners' linguistic competence as it is a waste of time, was well invested. In this sense, it is hoped that the study has made an original contribution to a critical issue which concerns teachers, learners and parents as well, namely, testing.

\section{References:}

Abanomey, A. (2002). The Effect of Test Authenticity on Reading Comprehension Test-taking Strategies Used by Adult Saudi Learners of English as a Foreign Language. Unpublished Doctoral Dissertation, Arizona State University, Tempe.

_ Allan, A. (1992). Development and Validation of a Scale to Measure Test-wiseness in EFL/ESL Reading Test-takers. Language Testing 9 (2), $101-122$.

_ Amer, A. (1993). Teaching EFL Students to Use a Test-taking Strategy. Language Testing 10, (1), 71-77.

- Anderson, J. (1989). Reading Comprehension Tests versus Academic Reading: What are Second Language Readers Doing? Unpublished Doctoral Dissertation, University of Texas, Austin.

_ Anderson, N. (1991). Individual differences in Strategy Use in Second Language Reading and Testing. The Modern Language Journal, 75, (4), $460-472$.

- Anderson, N., Bachman, L., Perkins, K., \& Cohen, A. (1991). An Exploratory. Study into the Construct Validity of Reading Comprehension Test: Triangulation of Data Sources. Language Testing, 8, (1), $41-66$.

_ Bachman, L. (1990). Fundamental Considerations in Language Testing. Oxford: Oxford University Press.

_ Cohen, A. (1991). Testing Linguistic and Communicative Proficiency: The Case of Reading Comprehension. In N. McGroarty \& L. Faltis (eds.), Languages in School and Society: Policy and Pedagogy. Berlin: Mouton de Gruyter, 383 - 408.

- ------ (1992). Test-taking Strategies on ESL Language Tests. MinneTESOL Journal, 10, $101-115$.

- ------- (1998). Strategies and Processes in Test-taking and SLA. In Bachman, L. \& Cohen, A. (eds.) Interface between Second Language Acquisition and Language Testing Research.

Harlow, Essex: Longman

- -------- (1999). Language Learning Strategies Instruction Research. In Catterall, S. \& Grabbem D. (eds.), Learner Autonomy in Language 
Learning: Defining the Field and Effective Change, pp. $61-68$. Frankfurt, Peter Lang.

-------- (2006). The Coming of Age for Research on Test-taking Strategies. Language Assessment Quarterly, 3 (4), 307 -331.

--------- (2007). The Coming of Age for Research on Test-taking Strategies. In J. Fox, M. Weshe, D. Bayliss, L. Cheng, C. Turner and C. Doe (eds.), Language Testing Reconsidered, pp. 89 - 111. Ottawa: Ottawa University Press.

-----------. Exploring Strategies in Test-taking: Fine-tuning Verbal Reports from Respondents. In G. Ekbatani \& H. Pierson (eds.) Learnerdirected Assessment in ESL, pp. 127 - 150. Mahwah NJ: Lawrence Erlbaum Associates, Inc.

_ Cohen, A. \& Upton, T. (2006). Strategies in Responding to the New TOEFL Reading Tasks (Monograph No. 33). Princeton, NJ: ETS.

_ Dörnyei, Z. (2001). Motivational Strategies in Language Classroom. Cambridge: Cambridge University Press.

_ Douglas, D. \& Hegelheimer, V. (2007). Strategies and Use of Knowledge in Performing New TOEFL Listening Tasks. Final Report to the Educational Testing Service, Princeton, NJ. Ames, IA: Iowa State University.

_ Driesbach, M. \& Keogh, B. (1982). Test-wiseness as a Factor in Readiness Test Performance of Young Mexican - American Children. Journal of Educational Psychology, 74, (2), 224-229.

_ Foster, D. \& Karn, R. (1998). Teaching TOEIC/TOEFL Test-taking Strategies. Paper Presented at the 32nd Annual Conference of the Teachers of English to Speakers of Other Languages. Seattle, WA, March 17 - 21, 1998 (ERIC Document Reproduction Service No. ED427543).

_ Gordon, C. (1987). The Effect of the Testing Method on Achievement in Reading Comprehension Tests in English as a Foreign Language. Tel Aviv: Tel Aviv University.

_ Green, A. (2007). IELTS Washback in Context: Perception for Academic Writing in Higher Education. Cambridge: Cambridge University Press.

_ Nevo, N. (1989). Test-taking Strategies on a Multiple-choice Test of Reading Comprehension. Language Testing, 6(2), 199-215.

_ Obah, T. (1993). Teaching an Examination Strategy to Technologyoriented University Students in Nigeria. Review of ELT, 3 (1), $80-86$. 
_ Phakiti, A. (2003). A Closer Look at the Relationship of Cognitive and Metacognitive Strategy Use to EFL Reading Achievement Test Performance. Language Testing, 20, (1), $26-56$.

_ Purpura, J. (1997). An Analysis of the Relationship between Test-takers' Cognitive and Metacognitive Strategy Use and Second Language Test Performance. Language Learning, 47 (2), 289 - 325.

_ Purpura, J. (1998). Investigating the Effects of Strategy Use and Second Language Test Performance with High - and Low-Ability Test-takers: A Structural Equation Modelling Approach. Language Testing, 15 (3), 333 -379 .

- Storey, P. (1997). Examining the Test-taking Process: A Cognitive Perspective on the Discourse Cloze Test. Language Testing, 14 (2), 214231.

- Taguchi, N. (2001). L2 Learners' Strategic Mental Processes during a Listening Test. JALT Journal, 23 (2), 176-201.

_ Tian, S. (2000). TOEFL Reading Comprehension: Strategic Uses by Taiwanese Students with Coaching-School Training. Unpublished Doctoral Dissertation, Teachers College, Columbia University, New York.

- Tsagari, C. (1994). Method Effect on Testing Reading Comprehension: How Far Can We Go? M.A. Thesis, University of Lancaster, (ERIC Document Reproduction Service No. ED424768)

- Yoshizawa, K. (2002). Relationships among Strategy Use, Foreign Language Aptitude, and Second Language Proficiency: A Structural Equation Modeling Approach. Unpublished Doctoral Dissertation, Temple University, Philadelphia, PA.

- Shohamy, E. (2001). The Power of Tests: A Critical Perspective on the Use of Language Tests. London: Longman.

_ Thompson, B. (2006). Foundations of Behavioral Statistics: An InsightBased Approach. New York, Guilford.

_ Tian, S. (2000). TOEFL Reading Comprehension: Strategies Used by Taiwanese Students with Coaching School Training. Unpublished Doctoral Dissertation. Teachers College, Columbia University.

- Vattanapath, R., \& Jaiprayoon, K. (1999). An Assessment of the Effectiveness of Teaching Test-taking Strategies for Multiple-choice English Reading Comprehension Test. Occasional Papers, 8, 57-71.

\section{溇溇溇溇溇}

